
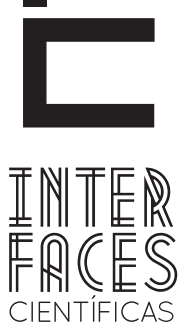

SAÚDE E AMBIENTE

\title{
DESENVOLVIMENTO SUSTENTÁVEL PARA O RESGATE DA CULTURA DO CACAU BASEADO NO APROVEITAMENTO DE RESÍDUOS
}

Astria Dias Ferrão Gonzales'

Arabella Varjão Damaceno Vital"
Jamille Macedo Lima"l

Mônica Bomfim Silva Rodriguesı

\section{RESUMO}

O Theobroma cacao L. denominado de cacaueiro é uma planta de importância econômica e principalmente cultural para a região sul da Bahia, conhecida como "Região Cacaueira", que produz o cacau, matéria-prima para a fabricação do chocolate. 0 declínio na produção de cacau, principalmente em função da "vassoura-de-bruxa", ocasionou mudanças regionais, nos aspectos sociais e econômicos. Com o surgimento de novas tecnologias, alterações na produção e no mercado do cacau, este trabalho tem como objetivo avaliar possíveis novas perspectivas para o aproveitamento integral do cacau de forma sustentável, incluindo a utilização dos resíduos de sua cadeia produtiva no campo da bioenergia, visto que a história da região sul da Bahia permanece vinculada à cultura do cacau. A casca do cacau pode ser aplicada na produção de biofertilizante, biogás, enzimas microbianas com segmentos biotecnológicos, briquetes, entre outros. A pesquisa foi realizada fundamentalmente por meio de revisão bibliográfica e dados secundários de órgãos de pesquisa vinculados ao cacau.

\section{PALAVRAS-CHAVE}

Cacauicultura. Biotecnologia. Resíduos. 


\section{ABSTRACT}

The Theobroma cacao L. called cacao is a plant of economic importance and cultural mainly to the south of Bahia, known as "Cocoa Region", which produces cocoa, raw material for the manufacture of chocolate. The decline in cocoa production, mainly due to the "witches' broom", resulted in regional changes in social and economic aspects. With the emergence of new technologies, changes in the production and marketing of cocoa, this study aims to evaluate new perspectives for the use of all cocoas in a sustainable manner, including the use of waste in the bioenergy field, since the history of southern Bahia remains linked to cocoa culture. The husk of cocoa can be applied in the production of biofertilizer, biogas, microbial enzymes with biotechnological segments, briquettes, among others. The research was conducted primarily through literature review and secondary data from research bodies linked to cocoa.

\section{KEYWORDS}

Cocoa. Biotechnology. Residues

\section{RESUMEN}

El Theobroma cacao L., llamado el árbol de cacao, es una planta de gran importancia cultural y económica, especialmente para la región sur de Bahia, conocida como "Región del Cacao", que produce la materia prima para la fabricación del chocolate. La disminución de la producción de cacao, principalmente debido a la "escoba de bruja", causó cambios regionales en los aspectos sociales y económicos. Debido a la aparición de las nuevas tecnologías, los cambios en la producción y comercialización de cacao, este estudio tiene como objetivo investigar las posibles nuevas perspectivas para el aprovechamiento integral del cacao de una manera sostenible, incluyendo el uso de los residuos de su cadena de producción en el campo de la bioenergía, ya que que la historia del sur de Bahia sigue vinculada a la cultura del cacao. La cáscara del cacao puede ser utilizada en la producción de biofertilizante, biogás, enzimas microbianas con segmentos biotecnológicos, briquetas, entre otros. La investigación se llevó a cabo principalmente a través de revisión bibliográfica y datos secundarios de los centros de investigación relacionados con el cacao.

\section{PALABRAS CLAVE}

Cacao. Biotecnología. Residuos

\section{INTRODUÇão}

O cacau é um fruto de valor cultural para o Brasil, mais especificamente na região sul da Bahia. No entanto essa cultura sofreu um declínio muito grande no final do século $X X$, o que fez com que se buscassem alternativas para sua recuperação.

$\mathrm{Na}$ cadeia produtiva do cacau é gerada uma grande quantidade de resíduo vegetal, que é subaproveitado, e novas tecnologias tem sido estimuladas para utilização e redução destes resíduos, para que o cacau possa ser aproveitado integralmente.
Della et al. (2005) avaliou os processos de reciclagem de resíduos agroindustriais e sugeriu que os resíduos industriais produzidos atualmente não podem mais ser definidos como lixo, e sim como substâncias residuais possíveis de serem utilizadas como matéria-prima ou como fonte de energia, sendo reciclado se houver incentivo suficiente.

Há uma crescente procura nas últimas décadas pela utilização dos resíduos agroindustriais, hoje denominada biomassa residual, devido ao aumento de sua produção graças ao aumento da população mun- 
dial e a consequente expansão das atividades agrícolas em toda planeta. Sendo boa parte dessa biomassa constituída de material de composição lignocelulósica, se apresenta hoje como uma fonte de matéria-prima renovável mais abundante encontrada na natureza. Os resíduos agroindustriais após o processamento de matérias-primas apresentam maior valor agregado, e pela vocação natural que o Brasil possui para sua geração acredita-se que o potencial de ganhos para o país seja de grandes proporções (CASTRO, 2010). Por outro lado, o acúmulo destes resíduos pelo seu não aproveitamento ou por descarte inadequado, gera dano ao meio ambiente e prejuízo de recursos, com contribuição significante para o problema da reciclagem e conservação da biomassa.

Os processos de reciclagem em geral vêm assumindo papel fundamental na agricultura sustentável, e sendo muito incentivados, já que podem contribuir positivamente para a minimização da poluição ambiental, além de permitir a valorização econômica desses resíduos. 0 resíduo necessita de destino adequado, e sua disposição no meio ambiente, através de emissões de matéria e energia depositada na atmosfera, água ou solo deve ocorrer nos padrões da legislação ambiental para não causarem poluição (PELIZER et al., 2007).

Segundo Miguel et al. (2008), no desenvolvimento da indústria de processamento mínimo de frutas e hortaliças em diversas partes do mundo, um dos principais entraves está associado à significativa quantidade de resíduos orgânicos que são gerados pela atividade.
Inúmeros procedimentos são criados para utilização desses materiais, transformando-os em bagaços para produção de enzimas lignocelulolíticas ou produtos com alto valor agregado como etanol, enzimas, ácidos orgânicos, aminoácidos e metabólitos secundários biologicamente ativos (ALEXANDRINO, 2007).

No Brasil são encontrados diversos tipos de resíduos agrícolas. Cada país ou região possui um resíduo específico devido à sua atividade agrícola ou industrial. No estado da Bahia, a produção cacaueira constitui uma importante atividade agrícola brasileira, a proporção aproveitável de subprodutos e resíduos do cacau é bastante expressiva. A casca do fruto do cacau normalmente não é aproveitada nas práticas de adubação do cacaueiro. Já o farelo de cacau é um subproduto gerado no processo de torrefação da amêndoa, na indústria, para a aquisição da manteiga do cacau e do chocolate, sendo utilizado de forma restrita, na alimentação animal em decorrência de uma substância tóxica chamada teobromina (PIRES et al., 2004).

O farelo e a casca do fruto do cacaueiro são o resíduo gerado em maior quantidade, podendo ser usado para produção de biogás, biofertilizantes, briquetes e também como substrato na produção de enzimas e assim o objetivo dessa pequena revisão é apontar para algumas perspectivas que poderiam ser utilizadas para agregar valor à lavoura cacaueira através do aproveitamento integral do fruto do cacau, ressaltando como esse uso ecológico da biomassa residual pode contribuir para o desenvolvimento da economia, de forma sustentável.

\section{MATERIAL E MÉTODOS}

Esta revisão bibliográfica sobre o uso dos resíduos do cacau foi realizada nas bases de artigos científicos Scielo (www.scielo.br), no NCBI (www.ncbi. nlm.nih.gov) e na Elsevier (www.elsevier.com), e bases de informativos, boletins e relatórios técnicos da Embrapa (Empresa Brasileira de Pesquisa Agropecuária) e Ceplac (Centro de Pesquisa da Lavoura Cacaueira). Também foram consultados os sítios de universidades à procura de monografias, dissertações e teses sobre o tema estudado, além de infor- 
mativos e notícias em jornais e revistas de divulgação. Para dados históricos sobre a lavoura cacaueira na Bahia e Brasil também foram consultados livros relacionados ao tema, e para os dados estatísticos foi consultado o IBGE (www.ibge.gov.br).

Os critérios estabelecidos para refinar os resultados foram o idioma, textos em português e inglês, utilizando-se como descritores (em português e de- pois traduzido para o inglês): cacau AND resíduos AND aproveitamento; cacau AND biofertilizantes; cacau AND biogás; cacau AND briquetes; cacau AND produção de enzimas, sem definição de data, porém priorizando artigos mais recentes, a não ser em casos de dados históricos. A seleção de dados foi feita a partir dos textos que faziam a correlação do uso dos resíduos de cacau para produção de bioprodutos com valor agregado possivelmente comprovado.

\section{RESULTADOS}

\subsection{HISTÓRICO DO CACAU NO BRASIL E NA BAHIA:}

O Cacau - Theobroma cacao L. - é uma fruta de origem americana, sendo o seu centro de origem, provavelmente, as margens dos rios Amazonas e Orinoco. 0 fruto apresenta um formato oval, de 20 a $30 \mathrm{~cm}$ de comprimento, e possui uma casca rígida que envolve as amêndoas, sendo esta de coloração vermelha ou amarela quando maduro. Sua árvore, denominada cacaueiro, mede de 1,50 a $2 \mathrm{~m}$ de altura. As amêndoas (sementes) são cobertas por uma polpa branca e utilizadas na obtenção do seu principal produto manufaturado, o chocolate, através de um processo artesanal de fermentação das sementes e posterior torrefação (OETTERER et al., 2006).

A cultura do cacau brasileiro se iniciou no século XVI na região Sul da Bahia, e gerou grandes mudanças econômicas e sociais, favorecendo por muitas décadas o crescimento e desenvolvimento desse local, de uma forma que nenhum outro produto conseguiu fazer. Os registros históricos mais antigos mostram que o cacaueiro foi introduzido no Sul da Bahia pelo colono francês Luis Frederico Warneaux, no ano de 1746, no município de Ilhéus (ANDRADE, 2003).

Em Ilhéus, o cacau adaptou-se perfeitamente às condições edafoclimáticas, trazendo muita prosperidade ao local, constituindo-se num dos pilares fundamentais para o enriquecimento de muitas famílias de ca- cauicultores e contribuiu muito para o desenvolvimento regional. Essa cultura continuou se desenvolvendo a partir daí e se estendeu até o sul do recôncavo baiano, extremo sul chegando até o estado do Espírito Santo, e deu denominação a essa região do sul baiano de "Região Cacaueira”, sendo os municípios de Ilhéus e Itabuna durante muitos os principais produtores de cacau do país (CUENCA; NAZÁRIO, 2004; OLIVEIRA, 2008).

O município de llhéus foi considerado o maior pólo cacaueiro da Bahia e o maior porto exportador de cacau no Brasil. $O$ auge da cultura do cacau foi no final do século XIX e início do século XX o Brasil chegou a ser o maior exportador mundial de cacau. A partir de 1976 o Governo Federal deu início, através da Ceplac, ao Plano de Diretrizes para a Expansão da Cacauicultura Nacional - o Procacau, que previa a implantação de 300 mil hectares de novos cacaueiros e a renovação de outros 150 mil hectares em plantações decadentes e de baixa produtividade da Bahia e Espírito Santo. 0 projeto objetivava a maximização da produção brasileira para elevá-la a um patamar de 700 mil toneladas de amêndoas secas/ano e garantir a consolidação do Brasil como principal produtor mundial.

A riqueza proveniente da cultura do cacau despertou o interesse da produção por outros países, o que causou 
o aumento da produção mundial, gerando a instabilidade do mercado internacional e consequente queda nos preços. Os baixos preços inviabilizavam a utilização intensiva de mão- de- obra e de capital no Brasil, levando ao abandono de lavouras, aumentando a incidência de doenças, reduzindo mais a produtividade (Figura 1).

A instabilidade vivenciada pelos homens do campo no sul da Bahia foi importunada pelas constantes crises da cultura agrícola cacaueira. A persistência do cultivo do cacau como economia monocultora e a relativa comodidade que era causada com essa cultura, deixou de certa forma, uma população despreparada frente a obstáculos, ocasionando saldos negativos na economia agrícola (SANTOS, 2009). Atualmente, o cacau ainda faz parte da economia da região sul da Bahia, e o Brasil, que participa no comércio internacional exportando cacau em amêndoas desde 1961; a partir de 1992, passou a ser também importador (CUENCA E NAZÁRIO, 2004).

O maior declínio da cacauicultura e da economia regional, além dos pontos já abordados, foi agravado pela praga que assolou a lavoura baiana, a "vassoura-de-bruxa”, a mais destrutiva doença do cacaueiro, causando enorme impacto socioeconômico negativo para a região. A vassoura-de-bruxa é uma doença causada pelo fungo Moniliophthora (=Crinipellis) perniciosa (Stahel), de acordo Aime e Phillips-Mora (2005). Em condições climáticas favoráveis e na ausência de cultivares resistentes, esse fungo pode causar até $100 \%$ de perdas de frutos (ANDEBRHAN et al., 1998; RIOS-RUIZ, 2002).

\subsection{NOVAS TECNOLOGIAS VOLTADAS PARA O CACAU VISANDO 0 DESENVOLVIMENTO SUSTENTÁVEL DA PRODUCC̄̃̃}

Atualmente, os centros de pesquisa científica e o mercado mundial estão atentos às tecnologias sustentáveis, que geram menor impacto na sociedade e propiciam retorno financeiro. A Biotecnologia, junto à Nanotecnologia tem contribuído muito nesse sentido, pois tratam de um conjunto de conceitos, co-
Figura 1: Produção de cacau no Brasil no período de 1960- 2010: 0 incremento na produção a partir do final da década de 70 foi incentivada muito em parte pelo PROCACAU, e o declínio esteve muito associado à disseminação da vassoura-de-bruxa, principalmente na região Sul da Bahia, e ao aumento da produção internacional, o que causou a redução dos ganhos com a lavoura cacaueira. Fonte: IBGE, Censo Agropecuário.

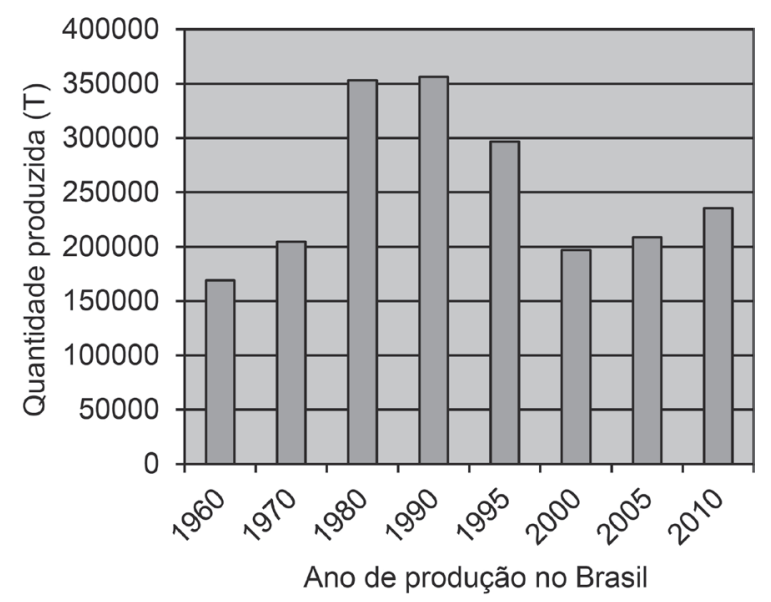

Atualmente o sul da Bahia não tem esse fruto como principal matéria-prima impulsionadora da economia local. Mas, devido à importância cultural desse fruto para a região, diversos esforços têm sido realizados na tentativa de melhorar essa situação, como por exemplo, através do desenvolvimento de tecnologias para recuperação e a diversificação da produção, estímulo de redução de geração de resíduos, e da utilização dos resíduos do cacau para produção de biofertilizantes, biogás, briquetes e enzimas microbianas para acelerar a produção de biocombustível, na intenção de agregar valor a esse produto e auxiliar na recuperação da lavoura cacaueira.

nhecimentos e de ferramentas experimentais que comportam um novo nível de domínio da matéria nas condições ambientes, instituindo novas estruturas organizadas a partir da escala molecular, dotadas de propriedades microscópicas e macroscópicas tornando-as adequadas a desempenharem funções 
necessárias à melhoria da qualidade de vida humana (GALEMBECK et al., 2009).

Visando diminuir o impacto ambiental e minimizar os custos de produção, a reciclagem dos resíduos orgânicos através do aproveitamento dos recursos naturais vem adquirindo valor na agricultura mundial. A agricultura sustentável aparece como uma perspectiva de um modelo capaz de compensar toda a atual situação do setor agrícola. Essa nova forma de se pensar a agricultura busca a maior produtividade possível com maior grau de preservação da natureza, compreendendo particularmente a preservação dos recursos naturais tais como o solo, o ar e a água (ALTIERI, 2000).

\subsection{BIOFERTILIZANTES}

O avanço no preço dos fertilizantes químicos, especialmente, aqueles derivados do petróleo tem reforçado o uso de resíduos agrícolas para essa finalidade, demandando da pesquisa maior atenção na procura de saídas para utilização econômica desses fertilizantes (CHEPOTE, 2003).

Um dos resíduos do cacau, por exemplo, a casca, é um subproduto que não é comumente aproveitado nas técnicas de adubação da planta na região Cacaueira do Sul da Bahia. Nas próprias unidades de produção, produtos como os estercos, palhas, camas de aviário, restos vegetais e compostos são preferencialmente utilizados para esse fim, como adubo orgânico.

Para aumentar o teor de matéria orgânica dos solos, uma maneira relativamente econômica e eficiente é através da adubação verde e do acréscimo de adubos orgânicos. As tortas oleaginosas, resíduo gerado após a extração do produto principal obtido de um vegetal, são resíduos orgânicos da agroindústria que também podem ser utilizados de diversas maneiras e isso também pode ser feito com os resíduos do cacau, tal como sua casca (TORO et al., 2008). Uma das aplicações para esse seria utilizar esses resíduos do cacau que são perdidos no
Diversas estratégias podem ser executadas neste modelo: o manejo dos recursos produtivos compõe um dos elementos técnicos básicos de uma estratégia de agricultura sustentável; a reciclagem dos nutrientes e matéria orgânica está integrada à utilização da biomassa das plantas (SILVA et al., 2004). E nesse último aspecto que alguns grupos tem investido seus esforços no sentido do aproveitamento integral do fruto do cacau para uso na produção de bioprodutos de interesse comercial e industrial, tais como biofertilizantes eco-compatíveis, ou ainda como matéria-prima para produção de biocombustíveis e de seus insumos.

campo, por não serem coletados e reciclados, como biofertilizantes.

Os biofertilizantes são assim chamados por serem compostos por material orgânico, geralmente residual, e possuem compostos bioativos, podendo ser de origem animal e vegetal. Em seu conteúdo são encontradas células vivas ou latentes de microrganismos, tais como diversos tipos de bactérias, leveduras, algas e fungos filamentosos e também metabólitos e quelatos organominerais (MEDEIROS e LOPES, 2006), fazendo desse produto, dependendo da sua origem e toxicidade, um excelente candidato a ser um biofertilizante.

Atualmente com a grande demanda por produtos orgânicos, que aumentou muito em todo mundo nos últimos anos, ainda são atribuídas ao biofertilizante mais vantagens, pois é já amplamente divulgado que os fertilizantes químicos podem causar problemas sérios à saúde humana se não manuseados corretamente pelos agricultores e principalmente se o alimento produzido na sua presença não for devidamente lavado e esterilizado no pós-colheita (PARIS, 2010). Os biofertilizantes não provocam problemas de salinização do solo, e se aplicam às exigências do cultivo mínimo, que é o plantio 
ou a semeadura da cultura com o mínimo de perturbação do solo, enquanto que os fertilizantes químicos são grandes reconhecidamente causadores da desestruturação e salinização do solo (MEDEIROS e LOPES, 2006).

No caso do cacau, Chepote et al. (2005) demonstrou que a aplicação de composto de casca de cacau, junto ao adubo mineral, promoveu incrementos significativos no crescimento do diâmetro do caule do próprio cacaueiro, além de um aumento significativo nas concentrações de

\subsection{BIOGÁS}

O biogás é um combustível gasoso com um teor energético alto idêntico ao gás natural, composto, principalmente, por hidrocarbonetos de cadeia curta e linear. Pode ser utilizado para geração de energia elétrica, térmica ou mecânica em uma propriedade rural, colaborando para a redução dos custos de produção (SIMS, 2003). O biogás e o biofertilizante muitas vezes podem ser produzidos a partir do mesmo resíduo orgânico, permitem aumento da produção agrícola e a transformação dos produtos tradicionais rurais, agregando valor, organizando a produção, aumentando a conservação dos produtos e melhorando a logística de comercialização para os agricultores familiares (QUADROS et al., 2010).

Até pouco tempo o biogás, era visto como um subproduto obtido pela decomposição de lixo urbano, do tratamento de efluentes domésticos e resíduos animais. Com o aumento dos preços dos combustíveis, o desenvolvimento econômico vem incentivando pesquisas de fontes renováveis para produção de energia, e criando novas formas de produção energética que possibilitam a redução da utilização dos recursos naturais renováveis (SALOMON; LORA, 2005).

Uma solução para o grande volume de resíduos produzidos por atividades agrícolas seria a transformação energética do biogás, diminuindo o material tóxico das emissões de metano produzindo energia elétrica, contribuindo com o meio ambiente agregando valor ambiental e redução de custos (COSTA, 2002). fósforo, magnésio e zinco na folha do cacaueiro e produção mais expressiva de cacau. Constatou também que o emprego de $4 \mathrm{~kg} /$ planta/ano de composto de casca do fruto de cacau ou de esterco de gado mais 50\% da adubação mineral (13\% N-35\% P205-10\% K20) gerou um incremento de $188 \%$ (de 527 para $1518 \mathrm{~kg} / \mathrm{ha}$ ). Esse uso seria excelente, pois o produtor de cacau usaria seu próprio resíduo da lavoura, reduzindo seus custos e aumento a quantidade produzida, podendo ainda obter um cacau de melhor qualidade.

O grupo potencial das matérias-primas para a produção de biogás engloba todos os resíduos orgânicos de fácil degradabilidade bacteriana. Estes resíduos orgânicos, de origem vegetal ou animal, como restos de verdura e de frutas, resíduos da produção de alimentos, esterco de animal não tem estabelecido legislação específica para seu tratamento adequado no Brasil (ROBRA, 2006; TAHERZADEH; KARIMI, 2008).

Mas os benefícios da utilização do biogás vão desde o fornecimento da demanda de energia em locais com altas taxas de produção dos resíduos orgânicos até uma possível solução das dificuldades de gerenciamento dos resíduos urbanos no Brasil. Na Tanzânia, uma experiência bem sucedida de produção de biogás a partir de resíduo vegetal foi feita com o sisal (Agave sisalana), um dos principais produtos agrícolas desse país, mas que produz uma quantidade enorme de resíduo (MUTHANGYA et al., 2009).

Seguindo esse exemplo, a casca do fruto do cacaueiro pode ser empregada na produção biogás em digestores, devido às sua característica composição química, rica em lipídios, fibras e carboidratos, na produção de gás metano. Deste modo, como citado no caso dos biofertilizantes, pode ser utilizado na propriedade, servindo para iluminação na cozinha e até para secagem de produtos agrícolas ou obtenção de energia elétrica, quando alimenta um conjunto motor-gerador (MENDES, 2000). 


\subsection{ENZIMAS}

As enzimas têm várias aplicações promissoras em uma variedade de segmentos biotecnológicos, como em indústrias de alimentos, de detergentes, na biotransformação de óleos e gorduras, obtenção de fármacos, tratamento biológico de águas residuárias, e biocombustíveis. As enzimas microbianas por sua vez, são produzidas e secretadas por microrganismos e são consideradas ainda mais atrativas para a indústria de transformação, onde a produção não estar dependente às questões sazonais e geográficas e pela possibilidade do uso de matérias primas de baixo custo (SOCCOL; VANDENBERGHE, 2003). Estas enzimas garantem um potencial de suprimentos e ainda possibilita a criação de novos sistemas enzimáticos, o que não acontece com as fontes animais e vegetais (ALVES et al., 2002; JAEGER; EGGERT, 2002). O Brasil apresenta um potencial elevado para a produção de enzimas microbianas devido à variedade de seus produtos naturais, e de microorganismos disponíveis para transformação de produtos úteis e de valor agregado (ZIMMER et al., 2009).

A fermentação em estado sólido (FES), que é um processo que se refere à técnica de crescimento de microrganismos em substratos sólidos umedecidos ou suportes inertes em ausência ou quase ausência de água livre, tem se mostrado como alternativa na produção de enzimas microbianas do ponto de vista ambiental, devido à possibilidade de utilização de resíduos e subprodutos da agroindústria como fonte de nutrientes e suporte para desenvolvimento do microorganismo e sua valorização e diminuição dos problemas causados na natureza (KRISHNA, 2005).

Alguns dos resíduos agroindustriais mais utilizados como substrato no processo de fermentação em estado sólido, são a polpa de café, farelo de cereais, palhas de arroz e trigo, bagaço de cana, cascas de frutas, batata, farinha de cereais, mandioca, entre outros (IBRAHIM, 2008). O grão do cacau é empregado para fabricação de chocolate e no momento do processamento origina um grande número de resíduo denominado farelo de cacau. Esse resíduo, além da própria casca do cacau pode ser triturado, esterilizado, e servir como substrato sólido para FES, fazendo assim um aproveitamento da biomassa residual de forma a produzir com baixo custo um produto de alto valor agregado, seguindo o modelo já empregado para outros diversos resíduos (SINGHANIA et al., 2009).

Portanto, estudos sobre o uso de diferentes substratos e microrganismos para a produção das enzimas microbianas em meio sólido podem colaborar com intuito de descobrir combinações ideais para obtenção de enzimas com rendimento elevado, empregando substratos e condições no processo que permitam a redução dos custos de produção em escala industrial.

Além disso, o próprio resíduo da lavoura cacaueira pode servir de fonte de microrganismos para serem utilizados na produção de enzimas microbianas. Silva (2011) testou leveduras isoladas durante o processo de fermentação do cacau quanto à secreção das enzimas amilases, celulases, pectinases, lipases, proteases e fosfolipases com o intuito de selecionar microrganismos com potencial de aplicação na obtenção de produtos ou no melhoramento de processos de importância biotecnológica. Verificou que leveduras isoladas da fermentação do cacau para fabricação do chocolate por secretarem as enzimas em tempo curto de crescimento e fermentação em caldo de cultura de custo baixo e em distintos valores de $\mathrm{pH}$, são capazes de ser uma fonte promissora de enzimas extracelulares de importância e aplicação industrial e biotecnológica. 


\subsection{BRIQUETES}

Briquete é um resíduo de biomassa denso por meio de um processo de compactação (RODRIGUES et al., 2002). Já a briquetagem é um processo de densificação energética de biomassa. São processos para transformar resíduo em combustível sólido. Este combustível sólido que pode ser de origem vegetal ou mineral, o briquete, pode ser uma excelente maneira de se acrescentar valor a matéria-prima e solucionar problemas ambientais e energéticos da região. Para tanto, pesquisas preliminares sobre as características físicas e químicas da matéria-prima básica dos bri-

\section{CONCLUSÃO}

A crise do cacau modificou bastante o aspecto social, ambiental e econômico da região cacaueira, instigando assim, a necessidade de buscar novas tecnologias, inovações no processo produtivo do fruto e na sua utilização. É importante aproveitar os projetos de agricultura alternativa, ressaltando a viabilidade econômica da cultura do cacau, que ocorrerá no aproveitamento integral de seus frutos (CARNEIRO et al., 2008). Estudos devem ser realizados visando novas estimativas na utilização dos resíduos de cacau, como combustível briquetado, para produção do biogás e de enzimas microbianas e utilização como biofertilizantes, a fim de favorecer 0 crescimento das regiões produtoras de cacau.

0 aproveitamento integral dos subprodutos e resíduos da pós-colheita do cacau é tema de pesquisa desenvolvida pelo Ministério da Agricultura/Ceplac, utilizando tecnologias que aperfeiçoem a produção cacaueira, resultando em acréscimo significativo da renda líquida do produtor de cacau, com menor dependên- quetes, devem ser realizados, visando obter resultados sobre o desempenho desse produto.

Trabalhos voltados ao aproveitamento da casca do cacau como briquete energético têm sido incentivados no intuito de gerar um destino proveitoso para os restos da lavoura do cacau. Cardoso (2002) relata que a casca do cacau é um resíduo com boa capacidade para produção de combustível briquetado. Fato que pode gerar agregação de valor a este resíduo e promover o desenvolvimento das regiões produtoras de cacau.

cia nas flutuações do mercado externo, que a o preço do produto. Um dado interessante demonstrado pela Ceplac sobre a importância de estudos para utilização desses subprodutos é que uma tonelada de cacau seco produz oito toneladas de casca fresca que são na maioria das vezes descartados (CEPLAC, 2012).

Em sendo assim, a viabilização de projetos para o desenvolvimento sustentável do cacau deve ser uma preocupação das autoridades, visto que a história do cacau na Bahia se entrelaça com a da região cacaueira, responsável por criar uma cultura no sul da Bahia determinada pela atividade agrícola.

Existem alternativas de agricultura, aplicáveis sem agredir o meio ambiente, que poderiam ocupar muitas áreas das fazendas. Para tanto, encorajam-se ações que sejam economicamente viáveis, com a preocupação voltada também para a questão socioambiental e de desenvolvimento da região cacaueira. 


\section{REFERÊNCIAS}

AIME, M.C.; PHILLIPS-MORA, W. The causal agents of witches' broom and frosty pod rot of cacao (chocolate, Theobroma cacao) form a new lineage of Marasmiaceae. Mycologia, v.97, p.1012-1022, 2005.

ALEXANDRINO, A. M. Aproveitamento do resíduo de laranja para a produção de enzimas lignocelulolíticas por Pleurotus ostreatus (Jack:Fr), Ciênc. Tecnol. Aliment., Campinas, v. 27, n. 2, p. 364-368, 2007.

ALTIERI, M. Agroecologia: a dinâmica produtiva da agricultura sustentável. 2.ed., Porto Alegre: Ed. Universidade/UFRGS, 2000.

ALVES, H.M.; CAMPOS-TAKAKI, A. M.; PORTO, A. L. F.; MILANEZ. A.I. Screenig of Mucor ssp. for production of amylase, lipase, polygalacturonase and protease. Brasilian Journal of Microbiology, v.33, 2002.

ANDEBRHAN, T.; ALMEIDA, L.C.; NAKAYAMA, L.H.I. Resistência de Theobroma cacao L. a Crinipellis perniciosa (Stahel) Singer: a experiência da Amazônia Brasileira. Agrotrópica, v.10, p.49-60, 1998.

ANDRADE, M. P. Ilhéus: Passado e Presente. 2. ed. Ilhéus: Editus, 2003.

CARDOSO, S. A.; SILVA, I. T.; ROCHA, B. R.; SILVA, I.M.O. Utilização de resíduos de cacau para a produção de energia no Estado do Pará. In: Encontro de Energia no Meio Rural, Campinas: 2002. Acesso em: 22 abr. 2012.

CARNEIRO, W.M.A.; BRAINER, M.S.C. P.; SANTOS, J.A.N. ;, SOUZA, G.S.; SILVA, C.E.G. A agroindústria de alimentos derivados de cacau no nordeste brasileiro. In: Congresso da Sociedade Brasileira de Economia, Administração e Sociologia Rural. 46. Rio Branco: Sober, 2008. p.1-21

CAStro, A. M. PEREIRA JUNIOR, N. Produção, Pro- priedades e Aplicação de Celulases na Hidrólise de Resíduos Agroindustriais. Quim. Nova, v.33, n.1, p.181-188, 2010.

CEPLAC. Cacau: história e evolução. Radar Cacau. Disponível em: <http://www.ceplac.gov.br/radar/radar_cacau.htm> Acesso em: 12 jan 2012.

CHEPOTE, R. E. Efeito do composto da casca do fruto de cacau no crescimento e produção do cacaueiro. Agrotrópica, v.15, n.1, p.1- 8. Ilhéus, 2003.

CHEPOTE, R.E.; SODRÉ, G.A.; REIS, E. L.; PACHECO, R. G.; MARROCOS, P. C. L. SERÔDIO, M. H. C. F.; VALLE, R. R. Recomendações de corretivos e fertilizantes na cultura do cacaueiro no sul da Bahia - $2^{\mathbf{a}}$ aproximação. Ilhéus: CEPLAC/CEPEC, 36 p., 2005.

COSTA, D.F. Biomassa como fonte de energia, conversão e utilização. Monografia. (Especialização em Energia). Instituto de Eletrotécnica e Energia (IEE) da Universidade de São Paulo, São Paulo, 2002.

CUENCA, M.A.G., NAZÁRIO, C.C. Importância Econômica e Evolução da Cultura do Cacau no Brasil e na Região dos Tabuleiros Costeiros da Bahia entre 1990 e 2002. Documentos 72- EMBRAPA Tabuleiros, Aracaju, 2004.

DELLA, V.P.; KÜHN, I. ; HOTZA, D. Reciclagem de Resíduos Agro-Industriais: Cinza de Casca de Arroz como Fonte Alternativa de Sílica. Cerâmica Industrial, v. 10, p. 22-25, 2005.

GALEMBECK, F.; BARBOSA, C.A.S.; SOUSA, R.A.. Sustainable use of biomass and natural resources for chemical innovation. Quím Nova, v.32, p.571-581, 2009.

IBGE. Banco de Dados Agregados. Sistema IBGE de Recuperação Automática - SIDRA. Disponível em: 
http://www.ibge.gov.br. Acesso em: 22 fev. 2012.

IBRAHIM, C.O. Development of applications of industrial enzymes from Malaysian indigenous microbial sources. Bioresour. Technol. v.99, n.11, p.4572-82, 2008.

JAEGER, K.E.; EGGERT, T. Lipases for biotechnology. Current Opinion in Biotechnology, v. 13, p.390-397, 2002

KRISHNA, C. Solid-state fermentation systems-an overview. Crit. Rev. Biotech. v.25, n.1-2, p.30, 2005.

MEDEIROS, M.B.; LOPES, J.S. Biofertilizantes líquidos e sustentabilidade agrícola. Bahia Agríc., v.7, n.3, nov. 2006.

MENDES, F. A. T. A cacauicultura na Amazônia brasileira: potencialidades, abrangência e oportunidades de negócio. Movendo Idéias, Belém, v. 5, n. 8, p.53 - 61, dez. 2000.

MIGUEL, A.C.A.; ALBERTINI, S.; BEGIATO, G.F.; DIAS, J.R.P.S.; SPOTO, M.H.F. Aproveitamento agroindustrial de resíduos sólidos provenientes do melão minimamente processado. Ciênc. Tecnol. Aliment., Campinas, v. 28, n. 3, p. 733-737, jul.-set. 2008.

MUTHANGYA, M.; MSHANDETE, A. M., KIVAISI, A. M. Two-stage fungal pre-treatment for improved biogas production from sisal leaf decorticorticarion residues. Int. J. Mol. Sci v.10, n.11, p.4805-4815, 2009. doi:10.3390/ijms10114805

OETTERER, M., REGITANO D’ARCE, M.A.B., SPOTO, M.H.F. Fundamentos de Ciência e Tecnologia de Alimentos. 613 p., Ed. Manole, São Paulo, 2006.

OLIVEIRA, U. B. (Re) organização da produção agropecuária e o contexto ambiental em Ibicaraí - BA 1990 a 2007. 99 f. Dissertação (Mestrado em Memória, Cultura e Desenvolvimento Regional) Uni- versidade do Estado da Bahia - UNEB Santo Antônio de Jesus - BA, 2008.

PARIS, C. M. Implantação de biodigestor e produção de biofertilizante. Dissertação (Graduação do Curso de Tecnologia em Biocombustíveis, Faculdade de Tecnologia de Araçatuba) Araçatuba, SP: Fatec, 2010.

PELIZER, L. H.; PONTIERI, M. H.; MORAES, I. O. Utilização de Resíduos Agro-Industriais em Processos Biotecnológicos como Perspectiva de Redução do Impacto Ambiental. Journal of Tecnhology Management \& Innovatium, v.2., 2007.

PIRES, A.J.V., CARVALHO JR., J.N.; SILVA, F.F.; VELOSO. C.M.; SOUZA, A.L.; OLIVEIRA, T.N.; SANTOS, C.L.; CARVALHO, G.G.P. BERNARDINO, F.S. Farelo de Cacau na Alimentação de Ovinos. Revista Ceres, v.51, n.293, p.33-43, 2004.

QUADROS, D.G.; OLIVER, A.P.M., REGIS, U., VALLADARES, R.; SOUZA, P.H.F., FERREIRA, E. J. Biodigestão anaeróbia de dejetos de caprinos e ovinos em reator contínuo de PVC flexível. Rev. bras. eng. agríc. ambient., v.14, n.3, p.326-332, Mar 2010.

RIOS-RUIZ, R.A. Melhoramento para resistência a doenças. In: DIAS, L.A.S. (Ed.). Melhoramento genético do cacaueiro. Viçosa: Funape; UFG, 2002. p.290-324.

ROBRA, S. Uso da glicerina bruta em biodigestão anaeróbica: Aspectos tecnológicos, ambientais e ecológicos. 116 p. Dissertação (Mestrado em Desenvolvimento Regional e Meio Ambiente) Universidade Estadual de Santa Cruz, Programa de Pós-Graduação em Desenvolvimento Regional e Meio Ambiente. Ilhéus, 2006.

RODRIGUES, L.D.; SILVA, I.T. ; ROCHA, B.R.P.; SILVA, I.M.O. Uso de briquetes compostos para produção de energia no estado do Pará. In: Procedings of the 4th Encontro de Energia no Meio Rural, 2002, Campinas (SP) [online]. 2002. 
SALOMON, K.R.; LORA, E.E.S. Estimativa potencial de geração de energia elétrica para diferentes fontes de biogás no Brasil. Biomassa \& Energia, v.2, n.1, p. 5267, 2005.

SANTOS, M.L. Migração e pobreza no sul da Bahia: A relação com a teoria da privação das capacidades. $6^{\circ}$ Encontro Nacional sobre Migrações. UNICAMP, 2009. Disponível em: <http://www.abep.nepo.unicamp.br/ docs/anais/outros/6EncNacSobreMigracoes/ST1/ MariaLuizaSilva.pdf> Acesso em: 21 abr. 2012.

SILVA, M.A.; MELO e SOUZA, R. e SOUZA, R.R. Biodegradação de resíduos agrícolas como alternativa à redução de riscos ambientais no semi-árido sergipano. II Encontro da ANPPAS, Indaiatuba, 2004.

\section{SILVA, M.S. Atividade enzimática extracelular de} leveduras isoladas da fermentação do. Cacau. 2011. 86 f. Dissertação (Mestrado em Biotecnologia). Universidade Estadual de Feira de Santana, Feira de Santana, 2011.
SINGHANIA, R.R., PATEL, A.K., SOCCOL, C.R., PANDEY, A. Recent advances in solid-state fermentation. Biochemical Engineering J., v.44, n.1, p-13-18, 2008. SOCCOL, C., VANDENBERGHE, L.P.S., Overview of applied Solid State Fermentation in Brazil. Biochemical Engineering J. v.13, n. 2-3, p. 205- 218, 2003.

TAHERZADEH, M.J.; KARIMI, K. Pretreatment of Lignocellulosic Wastes to Improve Ethanol and Biogas Production: A Review. Int. J. Mol. Sci. v.9, p.16211651; 2008. DOI: 10.3390/ijms90916212008.

TORO, M., BAZÓ, I.,LÓPEZ, M.. Micorrizas arbusculares y bacterias promotoras de crecimiento vegetal, biofertilizantes nativos de sistemas agrícolas bajo manejo conservacionista. Agronomía Trop. v.58, n.3, p.215-221, 2008.

ZIMMER, K.R.; BORRE, G.L.; TRENTI, D.S.; WOICICKOSKI, C.J.; FRASSON, A.P.; GRAEFF, A.A.; GOMES, P.; MACEDO, A.S. Enzimas Microbianas de uso Terapêutico e Diagnóstico Clínico, Revista Liberato, Novo Hamburgo, v.10, n.14, p.123-137, 2009.

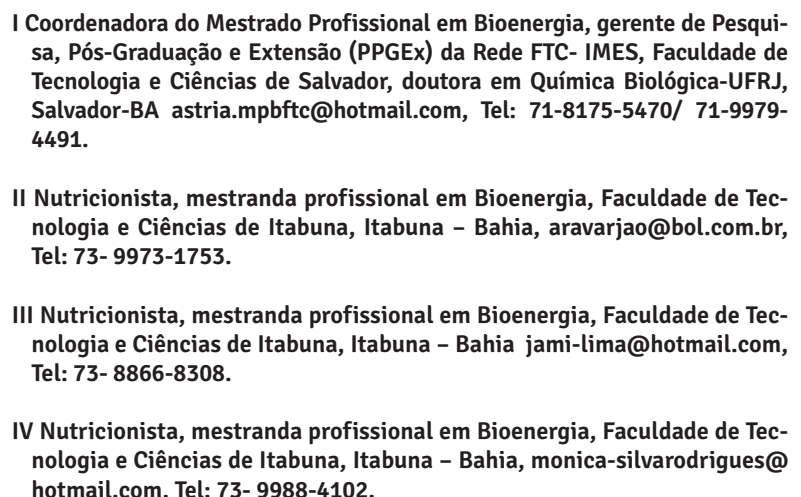

